\title{
Raising Awareness for Gender Equality in Hindu Marriage
}

\author{
Maryam Kaydani \\ Ph.D. Scholar, Law Department, Osmania University India
}

\begin{abstract}
The Hindu marriage has been one of the controversial issues among activities. Marriage in Hindu community is considered as holy and very significant social institution. In real, it is a commercial exchange and at large a marketplace populated by high demanding groom family. The paper aims to give a comprehensive account of problems that Hindu girls encounter during their marriage and within their marriage life. Apparently, Hindu marriage is between two families rather two people. More or less girls have no right to object. As a result girls mostly get married at earliest opportunity and they are forced into relationship as such most of marriage is based on parent's decision rather than mutuality of sentiment or emotional attachment. Therefore, prepubescent girls are often oppressed by bridegroom and his family members. In this sort of relationship, girls are financially dependent which develop their suppression. Data for this paper has drawn from in-depth interviews conducted with 120 married women of aged 12-20 years living in two Indian states who got married since 2005. Participants were randomly selected for interview if the woman was married before the ages of 15 years. Findings underscore the need to raise awareness of the negative outcomes of child marriage and to build support among girls and their families for delaying marriage, to enforce existing laws on the minimum age at marriage and to encourage other authorities to support young women in negotiating with their parents to delay marriage and eliminate child marriage.
\end{abstract}

Keywords: Child marriage, Women, Culture, Family, Society, Gender, India

\section{Introduction}

To Mytheli Sreenivas, in Indian society daughters are viewed as a "burden that they were eager to shove off onto groom's family" (104).

Child marriage is still rampant all around the world, particularly in countries with deep cultural and religious values and beliefs around marriage like India. Generally, Hindus arrange a marriage based on horoscopes read by pundits. It has been seen propose sustained just due to non-matching horoscope. Marriage is a very severe decision to be taken by individuals who have to be ready to spend the rest of their lives with someone of their choice. Of course, children are not that one as such children do not have a choice in this matter and mostly they are being forced, or else they are too young to realize what marriage means.

Yet, it mostly is cultural and religious tradition in many places and consequently problematic to change due to people cultural and religious beliefs in which tradition is considered valuable and should not be touched, particularly religious tradition, since changing it means asking people stop practicing religion, ritual ceremony which are a ultimate principle of democracy. The advantage of child marriages to lower cast is that child marriages are economical. Considering being protected or unavailable to other men also is one the cruxes bring about child marriage.

Notwithstanding, "harmful traditional customary practices such as early and forced marriage" is really a matter of concern (1). As such governments and civil society organizations are demanding to get laws against child marriage which is not working presently.

Child Marriage under Indian Law

Child marriage is complex subject under Indian law. The Child Marriage is set the minimum age of marriage for men as 18 , and women as 15 by Restraint Act in 1929, which is revised several times after India independence, especially in 1978 
when the marriage age was upstretched by 3 years each for men and women. However, according to The Prohibition of Child Marriage Act of 2006, the definition of child marriage updated by India which claims that

(a) to Hindus, Christians, Jains, Buddhists and those who are non-Muslims of India, and (b) outside the state of Jammu and Kashmir. For non-Muslim, The Prohibition of Child Marriage Act of 2006, "child marriage" is defined based on gender of the person - if a male; it is 21 years of age, and if a female, 18 years of age.

Hindu society has been always dealt with many problems regarding marriage which are due to different issue they encounter in their life .Mostly they cannot afford their children as such they would rather get rid of them and her expenditure. Therefore child marriage is customary in most Indian communities. As Rajendra Kumar Sharma in his book entitled Social Problems and Welfare (1998) argues that "The reasons behind child marriage in Hindu society were religious conservation, endogamy, sati custom, the custom of dowry and the joint family "(49-50). It means that there are several reasons behind child marriage. More, poverty is one of the significant issues that is ignored by Sharma. Even B.surresh Lal in child India "remains rooted in a complex matrix of religious traditions, social practices, economic factors and deeply rooted prejudices"(2993). As usual, children are victim of their societies. The other issue which is deal with child marriage is protecting the girl's sexuality, as Pierre Tristam in his article Child Marriage Facts, Causes and Consequences mentioned that 'In certain cultures, marriage a girl's family's honor on girl's individuality, in essence robbing the girl of her honor and dignity, undermines the credibility of family honor and instead underscores the presumed protection's actual aim: to control the girl. It means girls in this kind of family are victim of their close mind families and culture"(9). But what the concern is that girls are not matured physically or mentally and they are not able to provide binding commitment. Strong social and cultural standards also drive the practice regardless of legislation in place.

"Child marriages are accepted by and large in the society"( Tripurana Venkataratnam 5) and it has been occurred because of a diversity of various elements such as; poverty, absence of education, religion, culture ,custom and tradition, etc. This paper aims to investigate whether ethic and economy has more significant role in making girls to marriage?

Poverty is the main motivation of child marriage, child brides are mostly likely to be poor and remain poor, when poverty is sharp, parents are encouraged to married their daughter to detract family cost. Where family can't afford a proper dowry or bride's price is mostly a welcome income for this kind of families. As Anju malhotra in The Causes and Consequence and Solution to Forced Child Marrige in the Developing World claims that "For many poor families ,marring their daughter at an early age essentially is a strategy for economic survival, it is means one less person too feed, cloth and educate" (3) which means how families meet their problems.

Tradition, culture, religion and ethic are others issues that should be taken to the consideration. In many families, patents are under compression to get marry their daughters as early as possible for pull up her from sexuality energetic before marriage ,because they believe this kind of relationship before marriage can bring shame for families and marriage often defines a woman's condition in Hindu society ,parents are worry that if their girls not married according to social prospect cannot be able to get a good husband at all.

\section{Materials and Methods}

Materials: Data for this paper has drawn from in-depth interviews conducted with

120 married women of aged 12-20 years living in two Indian states who got married since 2005. Participants have been randomly selected for interview if the woman was married before the ages of 18 years.

Methods: Based on the interview, most of the cases hailed from poor and lower background which means they are from Dalit cast who are not illiterate except few (16 women). These women often suppressed by husband and his family members. They are mostly involved in domestic violence. The effect of age on involving violence cannot be ignored. Accordingly, women has been beaten by their husband and groom family and forced to work even during their pregnancy and doing hard work which is dangerous for them and their babies. The worse come worse when they deliver baby girls because none of the cultures are immune to predatory manners. Girls and women are still dealing with entrenched hostile attitudes towards them on a shocking scale. The callous behavior toward girls and women of lower casts in Hindu community is startling, not just in comparison with the men but also when paralleled to other women typically in India. 
The discrimination never ends there. Girls are more expected not to be properly concerned while the higher mortality rate geos to boys. A girl experiences much higher risk of malnutrition, illiteracy, child marriage and child labor than a boy. And very notably, a girl is unlikely to be able to choose when and whom to marry and more likely to have a say in domestic matters. Having to raise a daughter and expected to go in debt to pay the massive dowry which is the oppressive patriarchal culture of India means that many mothers are forced to abort as soon as they learn the baby is female. Hindu mothers who raise a fight or make too excessive fuss about getting rid of their daughter may be raped or beaten within an inch of their life (Of the total sample of 120 women were beaten at least once). Remarkably, all of them have been harassed both physically and verbally. The offender has been using knife or metal pipe which lead to victim injury and medical treatment (45 of the total sample of 120 women were victimized). Most of these women completely financially dependent and their incomes have been taken by their husband (103 of the total sample of women were dependent). All of them are staying in joint family. Unfortunately most of them are living in one room with in laws and their children that provided by the landlord who Result Child marriage and issues related to that was assessed using ten questions developed for the study and validated through rational and cognitive interviewing, none of them actually has aware being domesticated by their parents, husband or groom family. A typical issue has been "Have you had right to say no to your family for your marriage?" The questions in addition asked about their ethnic background or have been forced to marry or you married to consent your family, having problem with their husband or husband family. Women disclose that they have been not asked at the time of marriage whether they are happy with marriage or not. Further, their educational background has been asked to understand to what extent they are conscious about their right on marriage. They also asked about participating chore activities or its part of their responsibilities even when they work outside which reveals that most of them are maid or construction worker. Women have been then asked some more questions about the number of children and their husband family reaction toward the newborn baby sexuality and how their husband respond and adjust to their newborn baby in different ways. In addition how they spend their pregnancy whether they have been working or they were on leave for sometimes. Apart from this, whether they have any right over their salary or not? are working for. Most domestic violence occurred at victim's home and in front of their children. Domestic violence between parents has a deep and lasting impact on children. The majority of domestic violence has been committed against females compared to males. To some victims, intimate relationships with offenders may not be restricted to their husband rather they are harassed by their male in their families especially their son or father in law.

In this paper, it is considered the age of marriage which is child marriage in real and its consequences if it indicates in any of the ten questions about child marriage. The interview shows that child marriage and women involved in answered a series of questions on marriage issues and the causes of being victims and her age at the time.

These have been derived from qualitative research and interview. Each has presented as a statement and they have been asked to respond the questions (most of participants have been under legal age at the time of marriage) which indicating why their marriage is considered as child marriage and an explanation for why they did it. A typical item has been their family wanted to get rid of them or it has been societal and cultural forces item. These declarations have been asked separately for each of them or circumstance and some of differences between them explored and explained. Variables have been derived to groups to investigate the causes in motivation categories for those are into child marriage. Gender equality included responses to causes about being suppressed. The table 1 represents the number of participants in this study who have been engaged in child marriage.

The questions have been asked in interview included categorical variables that measuring age, ethnical background, employment, income , oppression ,position and frequency of literacy. Questions on the number of children and their sexuality included items on whether and how husband or husband family treated her and her children at the time of pregnancy and delivery. Scales have measured husband and husband family kindness and behavior (Of the total sample of 120 women). A typical item has been their literacy "no, I did not go to school, because my father could not afford it. The frequency of literacy represents (Of the total sample of 120 women have not even attended the school). 


\section{Discussion:}

Expending the samples, the paper summarized

sociodemographic characteristics for all women those have been interviewed. Of the total sample of 120 women, they have been selected only those who were married 2005 onward and at the time of the survey for statistical analysis, leaving an analytical model of 120 individuals. Then, in order to study the relationship between individual, household and domestic violence sociodemographic elements, being aware of their right by law, background and literacy, marital type, neighborhood, background, literacy, number of children, husband and groom family treatment, their assets, their children sexuality and others reaction and composite scores as the independent variables, and Subject characteristics

Women in both states had similar ethnicity, religion, illiteracy, offspring and they were labors as well. Women in both states have been more often child, having less literacy, and unaware of their own rights in marriage

\section{Marital Factors}

Approximately all of the women have been married before the age of reproductively, with $100 \%$ of marriages consisting of all were below 15 years, and 12 of the total sample of 120 women reporting being asked whether they are interested in their husbands while others have not been asked even. Women who are engaged in child marriage conception, reported domestic violence and social support as the outcome variables. The paper incorporated data on all women living in two Indian States Telangana and Andhra Pradesh in two ways. First, the researcher compared sociodemographic characteristics of women. Because samples for predetermined age categories with the intention of increasing the number of domestic violence and child marriage, the age distribution has been purposefully different from a participants who are representative of a continuous of child marriage trend. Second, for outcomes pertaining to literacy, regression analyses have been conducted in both States Andhra Pradesh and Telengana. which likely reflects the age-based sampling in this paper designed to include women behind their reproductive years. As with data analysis, women tended to be younger than other women. more often born in lower cast family, less literate, also they had fewer years of schooling, and had more children. They more often lived in a house that was owned by the household head and that had more inhabitants overall.

The outcome of this interview shows the women who got married in low age mostly they are involved in domestic violence rather than other women and they considered as others which Simone de Beauvoir heighten "One is not born, but rather becomes, a woman"(301). This kind of women are mostly being oppressed by their groom family, most of them are just maid for their family and even they have to work outside as a maid or as construction workers. It's so hard to believe even during their pregnancy they have to work. More or less they suffer from lack of self-confidence and they are depending on their husband. It's worst because they are working but they don't have any right over their outcome. Their outcome is often taken by husbands while mostly they don't do anything.

In this paper, the primary goal has been to examine whether marriage is a commercial exchange and comprehensive account of problems that Hindu girls encounter during their marriage and within their marriage life and trajectories of this women living in Urban in India. In order to paint a nuanced picture of familial and social context that may influence their life related to outcomes, the paper has been based on interviewed sources of social and support in their community. In addition, it has examined the effect of some familial or social factors such as age, education, ethnical background, employment, income and frequency of literacy which are the key elements in women's life. It demonstrates that these variables do significantly capture variability in during marriage or within marriage life. Local setting applied to their choices such as ethnics or social forces. Among the factors it is supposed that education, ethnical background are apparently heightened which may have significant implication for communication about marriage, family planning. Interestingly, an increase in even very less represent that they got familiar with their rights perhaps reflecting either aspects of familial or social life.

To make it clear, the interview represents that all women in this research are illiterate, from poor family and lower cast, low paid workers and unconscious about their right as human being or wife and they are victims of their poverty and attitude of their family. It demonstrates that ethnic group is one of the reasons of child marriage and a kind of a commercial exchange. And at large market, Indian marriage is populated by high demanding groom family. Hindu marriage is between to families rather than two people and mostly girls have no right to object and have to married at earliest opportunity which is mostly on parents' decisions. It also shows reproduction, these women at least have 2 or 3 children; the severity of deliver is undeniable, no healthy foods, clothing and etc. 
Unfortunately, all of them are more likely to engage in sexual intercourse at a young age, which in turn puts them at greater risk of teenage pregnancy. Pregnancy at young age can result in serious consequences, and it is dangerous and sometimes. It's worst when it meet children, they do not know how to behave their children well which causes so problems because they cannot support their children very well and children are sacrifice ignorance of their families. It is sign of a sexual discrimination, but the reaction of father and groom family is really different when the baby is girl and even the mother occurred in a very different environment.

\title{
Conclusion
}

Our findings about child marriage echo the concept of being girl in Hindu community they have highlighted (a) reluctance on the part of parents ethnics to endorse being opposed societal convention, because of keeping girls or iterating them it cost them legs and arm which seen as an indicator of being female; (b) significant misconceptions and in particular fears of the social consequences of side effects such as spinster; and (c) girls' willingness to get marry which it supports social and cultural notions that women should get married in the early years, eventually menstruation is considered as puberty.

With respect to marital status, child marriage is not support by the movement and even opposed activist struggles still is going on in Hindu community and ethnic is important in regulating social and labor dynamics within households and the power of groom family in affecting women's facing violence. However, women after marriage is not considered as part of their own family so their family are just a significant source of financial support. Furthermore, husbands and sons played great roles in their mother's marriage and life which pointing to a gendered division of male and female and social support.

Concerning on women situation it has showed those years of social progress with respect to female education and employment opportunities. However, some major mediators of social structure, such as child marriage, persist despite broad social changes is seems impossible. Poverty persists; child marriage remains normative; female education remains low, and violence remains a facet of life in these women.

\section{References}

[1] Malhotra,Anju. "The Causes and Consequence and Solution to Forced Child Marrige in the Developing World", International Center for Research on Women. July 15, 2010.

[2] Lal ,B.suresh. "Child Marriage in India: Factors and Problems", International Journal of Science and Research, 2015. 4 (4), 2993-2998.

[3] Maluleke, MJ. "Culture, Tradition, Custom, Law and Gender Equality". Potchefstroom Electronic Law Journal. 2012;15(1)1-22.

[4] Sharma, Rajendra Kumar. Social Problems and Welfare . Atlantic Publishers \& Dist, 1998. Print.

[5] Sreenivas, Mytheli. Wives, Widows, and Concubines: The Conjugal Family Ideal in Colonial India. Bloomington, IN: Indiana University Press,2008. Print.

[6] Tristam , Pierre.Child Marriage - Facts Causes and Consequences of Child Marriage and Sexual Abuse of Children. April 18, 2015. www.middleeast.about.com/

[7] Venkataratnam,Tripurana . Provide speedy justice to women victims. October 16,2014 www.thehansindia.com/

\author{
Appendix \\ How old did you get married? \\ Which kind of family are you from? \\ Have you gone to school? \\ How did you get familiar with your husband? \\ Have you had right to say no to your family for your marriage? \\ Do you live with your husband family? 6)Do they have good behavior with you? \\ Did you work in your pregnancy like before? \\ What did you face when you born baby girls? \\ Do you work out?
}

